\title{
A research on the relationship between academic entrepreneurs and enterprise performance: A three-dimension model
}

\author{
(C) Higher Education Press and Springer-Verlag 2008
}

\begin{abstract}
This study attempts to identify factors influencing the performance of enterprises established by academic entrepreneurs(AE) and to explore the relationship between these factors and enterprise performance. To this end, the authors propose a three-dimension model consisting of academic entrepreneurs' personal traits, human capital, and the entrepreneurial environment. Data of 84 AEs from 12 Chinese universities are used to empirically test and improve the model. Theoretical contributions and implications are also discussed.
\end{abstract}

Keywords academic entrepreneurs, enterprise performance, influencing factors

摘要 该研究的目的是考察影响学术型创业家所办公司绩效的因素, 以及这些影响 因素与企业绩效之间的关系。以中国大学环境中的学术型创业家为考察对象, 描述 了一个基于学术型创业家个人特质、人力资本、创业环境与企业绩效关系的三维分 析模型。对来自中国12所大学的84位学术型创业者的实证研究, 检验并修订了该理 论模型，为设计促进学术型创业家成长的政策找到了理论依据。

关键词 学术型创业家, 企业绩效, 影响因素

Translated and revised from Zhongguo ruankexue中国软科学(China Soft Science Magazine), 2006, 4(1): 124-129

CHEN Jin $(\triangle)$

College of Public Administration, Zhejiang University, Hangzhou 310027, China

E-mail: cjhd@zju.edu.cn

ZHU Xueyan

College of Public Administration, Zhejiang University, Hangzhou 310027, China

E-mail: xyz-93@163.com 


\section{Introduction}

In the process of "high-technologies development and industrialization", university scholars have played active roles in promoting and capitalizing knowledge or research results. A large number of enterprises originated from Chinese universities have gradually become significant participants in China's Hi-Tech industry. While more and more university scholars with academic achievements or scientific and technical knowledge entering into the business world and establishing enterprises of their own, AEs as a unique colony of entrepreneurs have increasingly drawn attention from practitioners and scholars alike.

At present, Chinese university researchers face a distinct entrepreneurial environment in a comprehensive transition from a planned economy to a market economy. Moreover, in the new era of knowledge-driven economy, Chinese AEs encounter countless entrepreneurial opportunities but also face harsher challenges.

In this paper, AEs refers to entrepreneurs with university teaching or research background on science and engineering disciplines. Different from the traditional entrepreneurs, AEs are multiple-talented entrepreneurs with both scientific spirit and market awareness. They actively participate in other activities such as community services, in addition to university research, teaching, and technology transfer.

Chinese AEs initially emerged in the 1980s. Since then, scholars, especially faculty from science and engineering universities or researchers from academe have engaged in a number of knowledge-dense industries, such as tech-consulting, technology transfers, Hi-Tech services, R\&D collaboration, technological park construction, or Hi-Tech start-ups (Xue, 2002). Statistics show that most enterprises established by AEs are located in the southeast of China and a vast majority of them focus exclusively on Hi-Tech industries, including info-tech, bio-tech, new materials manufacturing, and software. Benefited from advanced technologies of universities, Chinese AEs have successfully created a batch of Hi-Tech enterprises and famous brands. However, there are still a lot of problems in the AE type of enterprises, such as:

(1) Weak in marketing;

(2) Inefficient in internal administration, and poor risk-resisting ability;

(3) Fund shortage owing to slow capital accumulation;

(4) Conflicts between the "campus culture" and "corporate culture".

The purpose of this study is to delve deep into the factors influencing the performance of enterprises established by AEs, and to explore the relationship between these factors and enterprise performance. First of all, being an 
entrepreneur and a scholar at the same time, will these double identity influence AEs' enterprise performances? Also, profound changes have recently taken place in both Chinese universities and the business world, how will these changes affect AEs? So far, there have been few domestic studies focusing on this issue, to the authors' best knowledge. Last but not least, by comparison, AEs are least known among other types of entrepreneurs. Domestic studies focusing on the relation between $\mathrm{AE}$ and enterprise performances are still lacking. To deepen our understanding of AEs and to provide necessary guidance for AE enterprises, we need to study further on the issue. Questions to be answered in this paper can be summarized into $3 \mathrm{Ws}$, namely what are the determinants of the performance of $\mathrm{AE}$ enterprises? What are the basic attributes of these influencing factors? What is the relationship between these factors and $\mathrm{AE}$ enterprise performance?

\section{Theoretical background}

The term "academic entrepreneur" was first coined in a journal named Atlantic Monthly in 1965. It was originally used to portray a new type of professors who make full use of their academic reputation or expertise to actively participate in public affairs or business activities.

Between 1970s and 1980s, a growing number of scholars began to devote themselves full-timely to enterprise startups in Europe and North America. Influenced by this trend, academic researchers in universities or research centers became more utility-focused or profit-oriented. An investigation of 66 scholars in 4 departments of MIT led by Roberts and Peters (1986) revealed that about 70\% scholars conceived commercial goals or fancies in research activities.

In the 1990s, the research of industrialization of technological achievements expanded to both macro-layer upwards, which analyzed organizational features under different regimes and micro-layer downwards, which dug into specific projects.

In the 21st century, the theoretical research of $\mathrm{AE}$ has become more systematic. Meyer (2003) analyzed the mechanism of how academia - industries - government fashioned AE by cases descriptions in 2003, which was the first time to discuss AEs in multi-dimension environment and laid emphases on performance of $\mathrm{AE}$ in public supporting system and government incentives. Nevertheless, there are still certain deficiencies in the studies of $\mathrm{AE}$, for example, scholars are still quarrelling about the wordings and connotations of the term "academic entrepreneur". Furthermore, quite a few researches on "AE" lack systematic thinking. In addition, $\mathrm{AE}$ are limited to ordinary description in literature without putting them into entrepreneurial environment and treating them as a special research object (Miller and Garnsey, 1995). 


\section{Research method}

\subsection{Model}

In the extant literature, an "entrepreneur" is defined as a person participating in the initialization process of enterprises, having shares of entrepreneurial property and being concerned with enterprise management. Accordingly, we define AE from the following aspects: an AE's participation in the initialization process of enterprises endows him/her with prominent traits of entrepreneurs; having shares of entrepreneurial property urges him/her to care for the management and decision-making and thus having an inseparable relationship with enterprise performances, involvement in daily management enables him/her to form a set of managing patterns of his/her own, which gradually evolve into mature managerial thoughts and administrative systems.

As noted below, there are several problems in existing studies on AEs: First, the connotations of the term "AE" is still unclear; second, in most extant studies, the performances of enterprises established by AEs were measured only from a financial aspect. In view of these deficiencies, we proposed a "three-dimension" model consisting of personal traits of AE, human capital and entrepreneurial environment(See Fig.1). By studying comprehensively different factors influencing the performance of the enterprises established by AEs, we attempt to reveal the relation between these factors and enterprise performance (both financial performance and non-financial performance), hence provide managerial implications for practitioners and researchers alike.

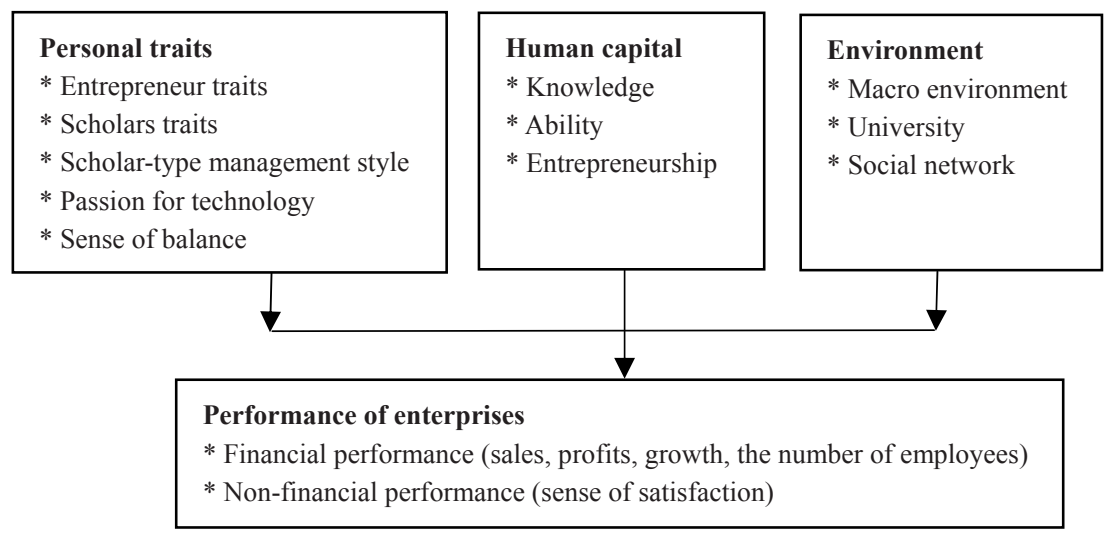

Fig. 1 Model of relationship between AE and enterprise performances

As shown in Fig.1, enterprise performance is determined by three factors, 
namely an AE's personal traits, human capital, and external environment. Specifically:

(1) The behaviors of AEs have been influenced by their personal traits, and over 20 kinds of entrepreneur traits are proved to have relations with the success of enterprises (Vine et al., 1993), which revealed that physiological variables and personal traits are important predictors of an enterprise's future performance (Frese, 2000). Personality psychologist Auport once defined the concept of personality as: "Personality is a dynamic composition of physiological system, and it is the special manner of individual to adapt to external environment". To be specific, personality is one of the most important physiological traits that have impacted on behaviors, and it decides the selection and direction of human behaviors. Besides, fine subculture of entrepreneurs is also a notable influencing factor when measuring enterprise performance (Bruno and Tybjee, 1996).

(2) From the perspective of human capital, education level, specialty background, experience of entrepreneurs, experience of business and commercial skills are influencing factors to enterprise performance. Cooper (1981) believed that experience and education are prerequisites to make decisions of starting a new undertaking, and influence performance at last. In the Upper Echelons Theory of Hambrick and Mason(1984), ability of strategic choice and performance level of an organization were influenced by managing background and knowledge character of the entrepreneur.

(3) External environment includes various factors such as national and local policies, qualities of public management, society and culture, families, as well as market, technology, material environment, regional and international economic and social correlative industry relation systems. All the factors have affected performance of individuals and collectives but the effects differ in time and area. In view of recent experience of political and macroeconomic reforms, the supportive environment of enterprises initialization matters a lot. Were the new enterprise to yearn for success and large profits, it would endure changes of itself and entrepreneurial behaviors and also would acquire resources from external environment, for example, venture capital, technology, labor force, loans, sustaining service and plentiful startup financing (Broph, 1989).

\subsection{Hypotheses}

\subsubsection{Relationship between AE's personal traits and enterprise performance}

Creativity is the most outstanding physiological trait owned by academic researchers. As former academic researchers, we considered that AE's personal traits include the ability of envisioning and association, keen intuition, plentiful 
inspiration, etc.

What characters should successful entrepreneurs be equipped with? The question has aroused heated discussions among academia. Brockhaus suggested that successful entrepreneurs have characters such as success motivation, endogenous control and venture tolerance et al. Successful entrepreneurs are bound to have abilities to suffer from venture and to master principles of market changes, and they also should have skills of technology and marketing and capabilities of management and cooperation. Casson (1982) and Caird (1998) put forward that there's an additional ability to identify potential opportunity.

With the rapid development of communication technology and other high-techs, global competition has risen to an unprecedented level. Under such circumstances, the ideology, managing style and expertise of AEs have displayed their unexcelled predominance. However, as former scholars, AEs also have some of typical scholar traits, which put them at a competitive disadvantage. For example, AEs tend to rely excessively on objective observation and their introvert personality as scholars do not agree with the fact that enterprise administration means making decisions under environment of great uncertainty and empowering with fine art. Hence, there would be growth choke points for AEs' enterprises if no breakthrough of these scholarly habits were to be made. Thus we promote a main hypothesis and three subsidiary hypotheses as below:

H1: The personal traits of an $\mathrm{AE}$ affect enterprise performance.

H1a: The entrepreneur trait of an $\mathrm{AE}$ is positively related to enterprise performance.

H1b: The typical scholar traits of an $\mathrm{AE}$ are negatively related to enterprise performance.

H1c: An AE's scholar-type of management style is positively related to enterprise performance.

\subsubsection{Relationship between AE's human capital and enterprise performance}

In this article, human capital of $\mathrm{AE}$ is the coagulation of his/her previous education, experience as entrepreneurs, expertise, and business skill. As one of the important resources of an $\mathrm{AE}$, the human capital is a basic resource of an enterprise and should be "used" with care.

Harhoff (1999) had done research about the relation between entrepreneur traits and enterprises' performance in German, and found that advanced education of entrepreneurs is positively pertinent to the increase of sales and productivity. Davidsson (1991) found experience and education of enterprise management had much impacts on entrepreneurs' abilities in Sweden. Robinson and Sexton (1994) discovered there is a plus correlativity between education level and self-employed income, and the research of 48 new enterprises in South 
Korea again revealed the plus correlation between education level and profits. As a result, we present a main hypothesis and 5 subsidiary hypotheses concerning an AE's human capital and enterprise performance.

H2: The human capital factors of an $\mathrm{AE}$ affect enterprise performance.

H2a: The advanced education level of an $\mathrm{AE}$ exerts certain effects on enterprise performance.

H2b: The complex knowledge background of an AE exerts certain effects on enterprise performance.

H2c: An AE's oversea studying experiences exert certain effects on enterprise performance.

H2d: An AE's academic title exerts certain effects on enterprise performance.

H2e: An AE's entrepreneurship is positively related to enterprise performance.

\subsubsection{Relationship between entrepreneurial environment and enterprise} performance

Covin and Selevin (1989) considered entrepreneurial environment as the reasonable cut-in point to enterprises analysis. At present, many governments are committed to promote entrepreneurial environment, in the purpose of upgrading enterprises' performance and boosting sustainable development of economy. In the present article, we analyze entrepreneurial environment from three aspects, including macro environment, university atmosphere and social network.

\subsubsection{Macro environment (e.g. government, culture)}

Macro environment embodies governmental administration, policies and laws, economic development and life environment, info-environment, and innovative culture and so on. To an enterprise, it is of great importance to strive for supportive environment.

3.2.3.2 University atmosphere (e.g. intangible assets, technological gardens of universities)

Universities possess a large amount of intangible assets. In addition, a university's "Brand Effect" helps lay solid foundation for rapid development of $\mathrm{AE}$ enterprises. Furthermore, technological gardens of universities will exert influence on development of enterprises in many aspects, such as establishing platforms for technological innovations and transfers, cultivating innovative environment, fostering elite, incubating technological enterprises and advancing technical transfers, etc. 
3.2.3.3 Social network (e.g. families, relatives and friends)

Whether families, relatives or friends have their own enterprises or not differentially influences an $\mathrm{AE}$ from different aspects, such as support of finance, support of advices, social relationship and commercial network.

Consequently, we present a main hypothesis, three subsidiary hypotheses presuming the relation between entrepreneur environment and enterprise performance as below:

H3: Entrepreneurial environment affects enterprise performance.

H3a: Supportive macro environment is positively related to enterprise performance.

H3b: Supportive academic environment of universities is positively related to enterprise performance.

H3c: Social network exerts certain effects on enterprise performance.

\section{Study procedure}

4.1 Method and results

84 AEs from 12 universities were surveyed. Data was analyzed using descriptive statistical analysis, reliability check, factor analysis and regression analysis with SPSS 11.5.

Regression analysis is a statistical method to find the relations among random variables (Ma, 2002). To find out the precise numerical equations between entrepreneurs' performance and the studied factors above, we applied single variable linear regression to independent variables (namely AE traits, human capital, entrepreneurial environment) and dependent variable (entrepreneur's performance). We used backward stepwise regression to eliminate the collinearity problem.

4.1.1 Regression analyses of factors influencing sales revenue in the previous year

Table 1 Results of backward stepwise regression model

\begin{tabular}{cccccc}
\hline Model & $R$ & $R^{2}$ & Adjusted $R^{2}$ & Std. error of the estimate & Durbin-Watson \\
\hline 1 & $0.593(\mathrm{a})$ & 0.352 & 0.273 & 0.690 & \\
2 & $0.593(\mathrm{~b})$ & 0.352 & 0.282 & 0.685 & \\
3 & $0.592(\mathrm{c})$ & 0.351 & 0.291 & 0.681 & \\
4 & $0.590(\mathrm{~d})$ & 0.348 & 0.297 & 0.678 & \\
5 & $0.584(\mathrm{e})$ & 0.341 & 0.299 & 0.677 & \\
6 & $0.578(\mathrm{f})$ & 0.335 & 0.301 & 0.676 & \\
7 & $0.568(\mathrm{~g})$ & 0.323 & 0.298 & 0.678 & 1.995 \\
\hline
\end{tabular}


Table 2 Regression analysis of factors influencing sales revenue in the previous year

\begin{tabular}{lcccrc}
\hline Factor & $\begin{array}{c}\text { Regression } \\
\text { coefficient }\end{array}$ & $\begin{array}{c}\text { Standard } \\
\text { deviation }\end{array}$ & $\begin{array}{c}\text { Standard } \\
\text { regression } \\
\text { coefficient }\end{array}$ & $\begin{array}{c}T \\
\text { value }\end{array}$ & $\begin{array}{c}\text { Sig. } \\
\text { level }\end{array}$ \\
\hline Constant & 3.321 & 0.074 & & 44.899 & 0.000 \\
A: Entrepreneur traits & 0.281 & 0.075 & 0.347 & 3.755 & 0.000 \\
B: Macro environment & 0.272 & 0.075 & 0.336 & 3.640 & 0.000 \\
C: Social network & 0.209 & 0.074 & 0.258 & 2.809 & 0.006 \\
\hline
\end{tabular}

Here, $F=12.724$, Sig. level $=0.000$, the significance level is relatively high. After 7 iterations, $D W=1.995$, there are 4 variables left in regression equation and the value of VIF is small enough, and collinearity problem is not significant.

Hence, we get the precise linear regression equation of sales as below:

$$
\text { Sales }=3.321+0.281 A+0.272 B+0.209 C
$$

4.1.2 Regression analysis of factors influencing enterprise profits

Table 3 Results of backward stepwise regression model

\begin{tabular}{cccccc}
\hline Model & $R$ & $R^{2}$ & Adjusted $R^{2}$ & Std. error of the estimate & Durbin-Watson \\
\hline 1 & $0.964(\mathrm{a})$ & 0.929 & 0.920 & 0.208 & \\
2 & $0.964(\mathrm{~b})$ & 0.928 & 0.921 & 0.206 & \\
3 & $0.964(\mathrm{c})$ & 0.928 & 0.922 & 0.205 & 1.721 \\
4 & $0.962(\mathrm{~d})$ & 0.926 & 0.920 & 0.207 & \\
\hline
\end{tabular}

Table 4 Regression analysis of factoring influencing enterprise profits

\begin{tabular}{lrrrrc}
\hline Factor & $\begin{array}{c}\text { Regression } \\
\text { coefficient }\end{array}$ & $\begin{array}{c}\text { Standard } \\
\text { deviation }\end{array}$ & $\begin{array}{c}\text { Standard } \\
\text { regression } \\
\text { coefficient }\end{array}$ & $\begin{array}{c}T \\
\text { value }\end{array}$ & $\begin{array}{c}\text { Sig. } \\
\text { level }\end{array}$ \\
\hline Constant & 3.667 & 0.023 & & 162.272 & 0.000 \\
A: Scholar traits & -0.172 & 0.026 & -0.234 & -6.647 & 0.000 \\
B: AE managing style & 0.095 & 0.024 & 0.130 & 4.062 & 0.000 \\
C: Entrepreneur traits & 0.305 & 0.044 & 0.416 & 6.994 & 0.000 \\
D: Ability acquirement & 0.196 & 0.041 & 0.267 & 4.767 & 0.000 \\
E: Entrepreneurship cultivation & 0.040 & 0.024 & 0.055 & 1.665 & 0.100 \\
F: University atmosphere & 0.204 & 0.039 & 0.277 & 5.219 & 0.000 \\
\hline
\end{tabular}

Here, $F=60.746$, Sig. level $=0.000$, the significance level is relatively high. After 7 iterations, $D W=1.721$, there are 6 variables left in regression equation and the value of VIF is small enough, and collinearity problem is not significant.

Hence,

$$
\text { Profits }=3.667-0.172 A+0.095 B+0.305 C+0.196 D+0.040 E+0.204 F
$$


4.1.3 Regression analysis of factors influencing enterprise growth

Table 5 Summary of backward stepwise regression model

\begin{tabular}{cccccc}
\hline Model & $R$ & $R^{2}$ & Adjusted $R^{2}$ & Std. error of the estimate & Durbin-Watson \\
\hline 1 & $0.824(\mathrm{a})$ & 0.679 & 0.640 & 0.444 & \\
2 & $0.823(\mathrm{~b})$ & 0.678 & 0.643 & 0.442 & \\
3 & $0.821(\mathrm{c})$ & 0.674 & 0.644 & 0.442 & \\
4 & $0.819(\mathrm{~d})$ & 0.671 & 0.645 & 0.441 & \\
5 & $0.815(\mathrm{e})$ & 0.664 & 0.643 & 0.443 & \\
6 & $0.812(\mathrm{f})$ & 0.659 & 0.641 & 0.444 & \\
7 & $0.808(\mathrm{~g})$ & 0.652 & 0.639 & 0.445 & \\
\hline
\end{tabular}

Table 6 Regression analysis of factors influencing enterprise growth

\begin{tabular}{lccccc}
\hline Factor & $\begin{array}{c}\text { Regression } \\
\text { coefficient }\end{array}$ & $\begin{array}{c}\text { Standard } \\
\text { deviation }\end{array}$ & $\begin{array}{c}\text { Standard } \\
\text { regression } \\
\text { coefficient }\end{array}$ & $\begin{array}{c}T \\
\text { value }\end{array}$ & $\begin{array}{c}\text { Sig. } \\
\text { level }\end{array}$ \\
\hline Constant & 3.631 & 0.049 & & 74.759 & 0.000 \\
A: Entrepreneur traits & 0.152 & 0.082 & 0.206 & 1.863 & 0.066 \\
B: Ability acquirement & 0.308 & 0.080 & 0.415 & 3.837 & 0.000 \\
C: University atmosphere & 0.194 & 0.080 & 0.263 & 2.437 & 0.017 \\
\hline
\end{tabular}

Here, $F=49.976$, Sig. level $=0.000$, the significance level is relatively high. After 7 iterations, $D W=1.952$, there are 3 variables left in regression equation and the value of VIF is small enough, and collinearity problem is not significant.

Hence,

$$
\text { Growth }=3.631+0.152 A+0.308 B+0.194 C
$$

4.1.4 Regression analysis of the factors influencing the number of employees

Table 7 Results of backward stepwise regression model

\begin{tabular}{cccccc}
\hline Model & $R$ & $R^{2}$ & Adjusted $R^{2}$ & Std. error of the estimate & Durbin-Watson \\
\hline 1 & $0.906(\mathrm{a})$ & 0.822 & 0.800 & 0.327 & \\
2 & $0.906(\mathrm{~b})$ & 0.822 & 0.803 & 0.325 & \\
3 & $0.906(\mathrm{c})$ & 0.822 & 0.805 & 0.323 & \\
4 & $0.906(\mathrm{~d})$ & 0.821 & 0.808 & 0.321 & \\
5 & $0.905(\mathrm{e})$ & 0.820 & 0.808 & 0.320 & 2.050 \\
6 & $0.902(\mathrm{f})$ & 0.814 & 0.805 & 0.323 & \\
\hline
\end{tabular}


Table 8 Regression analysis of factors influencing the number of employees

\begin{tabular}{lccrrc}
\hline Factor & $\begin{array}{c}\text { Regression } \\
\text { coefficient }\end{array}$ & $\begin{array}{c}\text { Standard } \\
\text { deviation }\end{array}$ & $\begin{array}{c}\text { Standard } \\
\text { regression } \\
\text { coefficient }\end{array}$ & $\begin{array}{c}T \\
\text { value }\end{array}$ & $\begin{array}{c}\text { Sig. } \\
\text { level }\end{array}$ \\
\hline Constant & 3.679 & 0.035 & & 104.408 & 0.000 \\
A: Scholar traits & -0.131 & 0.040 & -0.179 & -3.262 & 0.002 \\
B: Entrepreneur traits & 0.221 & 0.064 & 0.303 & 3.432 & 0.001 \\
C: Ability acquirement & 0.164 & 0.061 & 0.224 & 2.703 & 0.008 \\
D: University atmosphere & 0.296 & 0.060 & 0.405 & 4.919 & 0.000 \\
\hline
\end{tabular}

Here, $F=96.512$, Sig. level $=0.000$, the significance level is relatively high. After 6 iterations, $D W=2.050$, there are 4 variables left in regression equation and the value of VIF is small enough, and collinearity problem is not significant.

Hence,

Number of employees $=3.679-0.131 A+0.221 B+0.164 C+0.296 D$

4.1.5 Regression analysis of factors influencing an AE's sense of satisfaction

Table 9 Results of backward stepwise regression model

\begin{tabular}{cccccc}
\hline Model & $R$ & $R^{2}$ & Adjusted $R^{2}$ & Std. error of the estimate & Durbin-Watson \\
\hline 1 & $0.762(\mathrm{a})$ & 0.580 & 0.529 & 0.559 & \\
2 & $0.762(\mathrm{~b})$ & 0.580 & 0.535 & 0.556 & \\
3 & $0.761(\mathrm{c})$ & 0.579 & 0.540 & 0.553 & \\
4 & $0.759(\mathrm{~d})$ & 0.576 & 0.543 & 0.551 & \\
5 & $0.757(\mathrm{e})$ & 0.573 & 0.546 & 0.549 & 2.032 \\
6 & $0.753(\mathrm{f})$ & 0.567 & 0.546 & 0.549 & \\
\hline
\end{tabular}

Table 10 Regression analysis of factors influencing an AE's sense of satisfaction

\begin{tabular}{lrcrrc}
\hline Factor & $\begin{array}{c}\text { Regression } \\
\text { coefficient }\end{array}$ & $\begin{array}{c}\text { Standard } \\
\text { deviation }\end{array}$ & $\begin{array}{c}\text { Standard } \\
\text { regression } \\
\text { coefficient }\end{array}$ & T value & $\begin{array}{c}\text { Sig. } \\
\text { level }\end{array}$ \\
\hline Constant & 3.714 & 0.060 & & 61.953 & 0.000 \\
A: Scholar traits & -0.151 & 0.065 & -0.186 & -2.315 & 0.023 \\
B: AE managing style & 0.153 & 0.060 & 0.187 & 2.529 & 0.013 \\
C: Entrepreneur traits & 0.264 & 0.095 & 0.324 & 2.783 & 0.007 \\
D: University atmosphere & 0.330 & 0.098 & 0.405 & 3.359 & 0.001 \\
\hline
\end{tabular}

Here, $F=25.909$, Sig. level $=0.000$, the significance level is relatively high. After 6 iterations, $D W=2.032$, there are 4 variables left in regression equation and the value of $V I F$ is small enough, and collinearity problem is not significant.

Hence,

Sense of satisfaction $=3.714-0.151 A+0.153 B+0.264 C+0.330 D$ 


\subsection{Discussion}

Drawing on the above regression results, we explored the relationship between AEs and factors influencing their enterprises' performance. Below is a depiction of the relation between enterprise performance and its influencing factors.

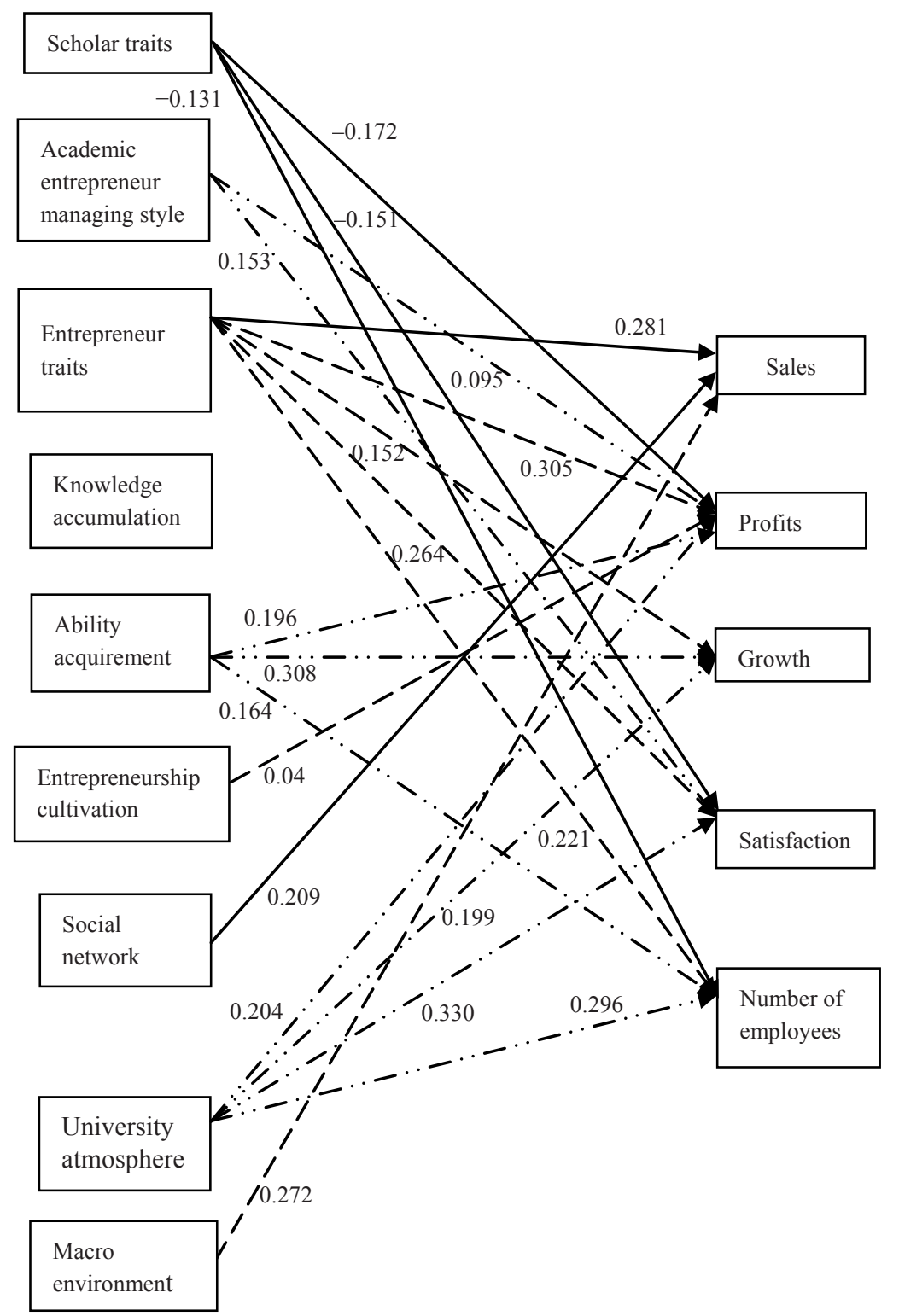

Fig. 2 Relationship between Influencing factors and performance of an AE's enterprise 


\subsubsection{Influencing factors (independent variables)}

As Fig.2 shown:

(1) The variable of "entrepreneur traits" deserves greater emphasis, which has effects on all aspects of enterprise performance. The result indicates that when a scholar starts up a business or manages an enterprise, his needs to be more focused on his identity as an entrepreneur, as "entrepreneur traits" is a vital factor influencing enterprise performance.

(2) One of the components of entrepreneurial environment-university atmosphere has many contributions to AE's enterprise performance in sales revenue, enterprise growth, AE's sense of satisfaction, and the number of employees. As former university professors, AEs tend to maintain a close relationship with their alma universities and make full use of the prestige and resources of the universities not only at times when they start new businesses but also when they manage enterprises in the long run.

(3) However, the above results show that typical scholar traits of AEs are detrimental to enterprise performance in terms of profits, sense of satisfaction and the number of employees. Why? Possible explanations may be that AEs, whose early experiences as academic researchers have cultivated habits of excessive dependence on objective measures and precise numbers. Sometimes, an AE's over-emphasis on "analysis" leads to low efficiency in their enterprises, which in turn causes low sense of satisfaction and other problems. In addition, basically introverts, many AEs have difficulties in the art of empowerment and they usually lack the capacity of interpersonal communication.

\subsubsection{Influencing factors (dependent variables)}

\subsubsection{Financial performance}

Sales: When entering the variables of entrepreneur traits, social network and macro environment into the equation of sales (1), the results indicated that "entrepreneur" is the core of the whole organization. Entrepreneur traits, therefore, are the watershed between "entrepreneurs" and "traditional managers". Also, as Chinese people highlight inter-relationship among people (popularly known as "Guanxi"), we also found from Fig.2 that social network and macro environment such as policies are key factors influencing enterprise sales revenue.

Profits: Except the typical scholar traits, which have negative impact on profits (due to the reasons discussed above), the other five factors entered Equation (3) all positively related to enterprise profit.

Growth: Fig.2 shows that entrepreneur traits, ability acquirement and university atmosphere are the key factors influencing the growth of an AE's 
enterprise.

Number of employees: Fig.2 shows that scholar traits, entrepreneur traits and ability acquirement are the key factors influencing the number of employees in an AE's enterprise.

\subsubsection{Non-financial performance}

As shown in Fig.2, factors influencing an AE's sense of satisfaction are AE's academic traits, AE's management style, entrepreneur traits and university atmosphere. Except the variable of academic traits, the other three are positively related to an AE's sense of satisfaction.

(1) Scholarly traits once again turn out to be an adverse factor. Maybe it can be explained that at the beginning of enterprise establishment, AEs just have superficial understanding of "entrepreneur", and in most situations, they manage their enterprises in the same way as they do on campus, resulting in quite a few setbacks, and these setbacks in turn lead to low sense of satisfaction among AEs.

(2) The other three factors are positively related to an AE's sense of satisfaction. Extant research showed that university scholars employ themselves in enterprise out of diverse intentions. They not only pay attention to economic profits and successful transformation from technology to industry, but also put stress on recognition of market and respect from employees. Since a variety of intentions can agitate their excitement compared with a single aim - profits, they are prone to obtain higher interior satisfaction.

\section{Conclusion}

In a new era of knowledge economy, AEs with technology expertise, managerial experiences, and abilities to think strategically are bound to play more important roles in our society. To deepen our understandings of AEs and to facilitate AEs to fulfill their missions, more researches on AEs are needed and more supports from government departments and universities are indispensable.

\section{References}

Chirstian B, Pierre-andre J(2000). Defining the field of research in entrepreneurship. Journal of Business Venturing, 16(2): 165-180

Cooper A C, Gimeno-Gascon F J, Woo C Y(1994). Initial human and financial capital predictors of new venture performance. Journal of Business Venturing, (5): 371-395

Damian M, Elizabeth G(2000). Entrepreneurs and technology diffusion: How diffusion research can benefit from a greater understanding of entrepreneurship. Technology in 
Society, 22: 445-465

Hannu L(2000). Entrepreneurship and the characteristics of the entrepreneurial personality. International Journal of Entrepreneurial Behavior and Research, (6): 295-309

Henry E, Webster A, Gebhardt C, Regina B, Terra C(2000). The future of the university and the evolution of ivory tower to entrepreneurial paradigm. Research Policy, 29: 313

Lewis M B(2002). From invention to innovation. Proceedings of US-China Seminar On Technical Innovation, Cambridge, MA: Harvard University Press

Martin M(2003). AE or entrepreneurial academics? Research-based ventures and public support mechanisms. R\&D Management, (2): 107-115

Zahra S S(1993). Environment, corporate entrepreneurship, and financial performance: A taxonomy approach. Journal of Business Venturing, (8): 319-340

Zenas B, MacMillan I C(1993). Corporate Venturing. Boston, Massachusetts: Harvard Business School Press 